\title{
Russian and foreign steam generators for NPP power units with wet steam turbines
}

\author{
Mikle Egorov ${ }^{1,2, *}$, Ivan Kasatkin ${ }^{1}$, Ivan Kovalenko ${ }^{2}$, Irina Krectunova ${ }^{2}$, Nataliya Lavrovskaya $^{2}$, and Nadezhda Litvinova ${ }^{2}$ \\ ${ }^{1}$ Peter the Great St. Petersburg Polytechnic University, Russia, 195251 Saint-Petersburg, Polytechnicheskaya 29 \\ ${ }^{2}$ St. Petersburg State University of Aerospace Instrumentation, Russia, 190000 Saint Petersburg, Bolshaya Morskaya st. 67
}

\begin{abstract}
The main aim of the current study is to analyze advantages and shortcomings of horizontal and vertical types of steam generator design. Design solutions and experience of operation of steam generators of horizontal type accepted in Russia and of vertical type applied by Westinghouse, Combustion Engineering, Siemens, Mitsubishi, Doosan were analyzed within the framework of the present study. It was established that steam generator equipment of horizontal type is characterized by disadvantages of design, technological and operational nature. Thus, horizontal steam generators with dimensions permissible for railroad transportation and, for VVER-1200 with reactor vessel diameter equal to $5 \mathrm{~m}$, by water transport as well, have exhausted the possibilities for further significant increase of the per unit electric power. The demonstrated advantages of vertical-type steam generators are as follows: 1) absence of stagnant zones within the second cooling circuit; 2) uniformity of heat absorption efficiency of the heating surface that ensures improved conditions for moisture separation; 3) increased temperature drop with parameters of generated steam elevated by $0.3-0.4 \mathrm{MPa}$. Conclusion was made on the advisability of introduction of steam generators with vertical-type layout in the Russian nuclear power generation.
\end{abstract}

\section{Introduction}

Steam generator is one of the most important elements of a nuclear power installation. Its purpose is to produce water steam - the working medium of the power generation cycle. Steam production is associated with the following complex processes $[1,2]$ :

- Transfer of heat from heat transfer fluid of the NPP primary cooling circuit to the heated water of the secondary cooling circuit;

- Conversion of thus heated water into water steam;

- Circulation of steam-water mixture;

- Separation of water from steam.

A significant part of emergency shutdowns of NPPs is caused, in particular, by failures of steam generators $[3,4]$.

Steam generator for VVER-1000 power unit (Figure 1) is a large-sized equipment with vessel length of 14.5 $\mathrm{m}$ and diameter up to $4.2-4.3 \mathrm{~m}$. Russian NPPs equipped with VVER-1000 reactors have four-loop cooling configuration, i.e. each power unit incorporates four steam generators occupying significant space inside the containment shell of the reactor unit. The larger are the dimensions of the containment shell the higher is its cost. Containment shell must be strong enough, i.e. it must be capable to withstand excess pressure of steamwater mixture in case of an accident accompanied with a failure of pressurization in the primary cooling circuit. The larger is the diameter of the shell which is a pressurized vessel, the more difficult it becomes to ensure its strength.

Comparative analysis of contemporary design of steam generators and earlier design configurations presented, for instance, in [5], demonstrated that during the period of development of "large-scale" nuclear power generation industry beginning from the time of its initiation, design layouts of steam generators remain practically unchanged.

The positive side of such conservatism is associated with the fact that the design solutions supported by several decades of practical application in the process of development of different technical fields including power generation, ship building and chemical technologies, allow obtaining in many cases durable and reliable equipment.

The negative side of such conservatism amounts to obtaining equipment with excessive mass and, consequently, increased metal consumption and, in separate cases, equipment which is not sufficiently reliable when unfavorable processes must be dealt with in the process of operation of such equipment.

Corresponding author: mikhail.yu.egorov@ gmail.com 

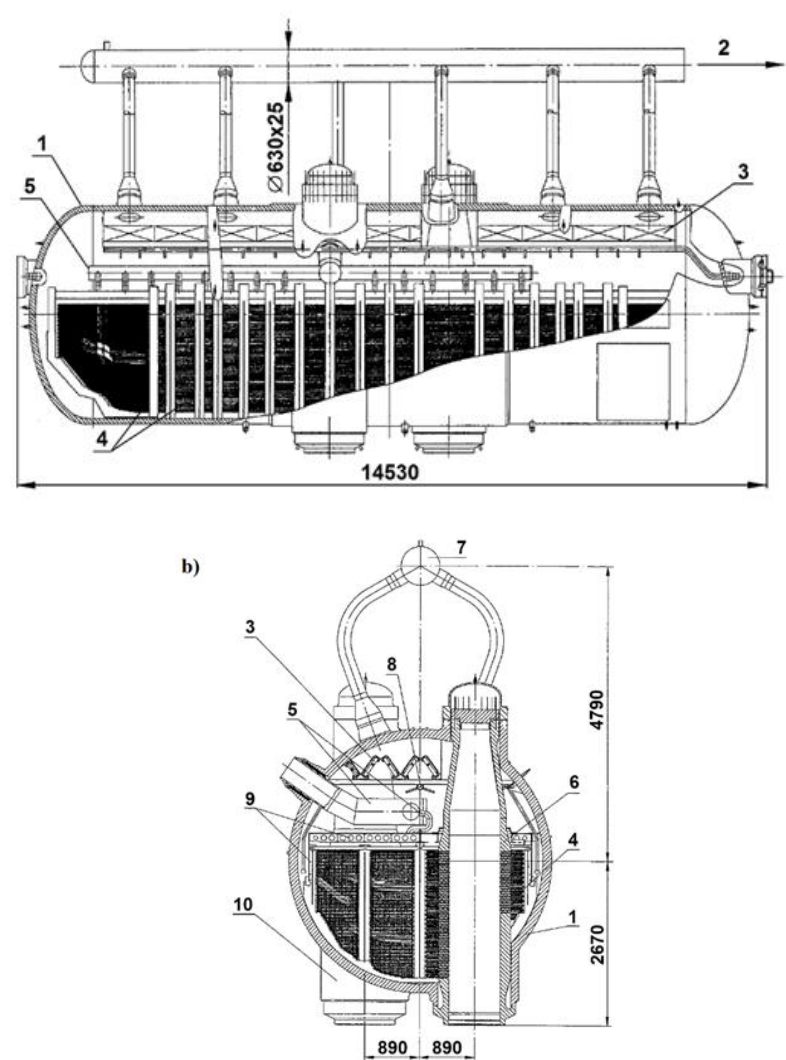

Fig. 1. Horizontal type steam generator for VVER -1000 (Unit 5 Novovoronezh NPP): a) - longitudinal section, b) - crosssection, 1 - vessel; 2 - steam outlet; 3 - chevrons of the separator unit; 4 - heat exchange tube bundle; 5 - supply of feed water; 6 - outlet header; 7 - steam header; 8 - supply of auxiliary feed water; 9 - tube bundle support; 10 - inlet header.

Let us analyze the advantages and drawbacks of design solutions and organization of working processes in steam generators for the purpose of search for the potential for enhancement of per unit power of power units of nuclear power installations equipped with light water nuclear power reactors and enhancement of parameters of the generated steam.

\section{Results and Discussion}

\subsection{Steam generators of horizontal type}

Steam generators of horizontal type are used on NPPs with VVER reactors from the moment of initiation of development of nuclear power generation [6].

\subsubsection{Advantages of the design}

1. The design is relatively straightforward and simple: manufacturing of chevron-type separation devices is simpler as compared with swirl-vane separators.

2. Dimensions allow railroad transportation of the equipment.

3. Absence of thick flat tube sheets. Heating medium headers have cylindrical shape.

The first horizontal steam generators were used in relatively low-power nuclear installations with low parameters of steam which were intended for different applications (not power generation).

Starting from 1964, steam generators of horizontal type were used in power units of the Novovoronezh NPP with per unit electric power of 210, 365 and $440 \mathrm{MW}$. Operation of this equipment proved to be reliable enough.

\subsubsection{Shortcomings of the design revealed in the process of operation of Russian NPPs}

Fractures in the header structures took place already during the initial period of operation of VVER-440 power units. In case of fluctuation of water level inevitable on NPP, variable cyclic thermal stresses can develop within the header wall. This problem was successfully resolved by sealing voids between the steam generator partitions protecting the header wall in the region of water level fluctuations from direct contact with water of the secondary cooling circuit. Prior to that, inadequate sealing of the voids resulted in the contact between the relatively cool water with relatively hot header walls.

Horizontal PG-1000 steam generators were introduced during the subsequent period of operation initially of Unit 5 of the Novovoronezh NPP followed by other NPP power units. In the course of transition from power installation with VVER-440 to significantly higher electric power (1000 MW), design of horizontal steam generators reached their limiting thermal hydraulic characteristics.

Besides the above considerations, the external dimensions of steam generators are limited by the requirements of their transportation by railroad transport. Therefore, it was necessary to in-crease specific thermal and steam loads by more than two times and to reduce factual inventories as refers to water level in the secondary cooling circuit and the emergency reserve of this boiler water in the shell in the case of accident of the "feed water supply break" type. These restrictions initiated certain negative consequences - 45 steam generators had to be replaced on the Novovoronezh, South Ukraine, Zaporozhye and Balakovo NPPs [7]. The main cause that prompted the necessity of replacement of steam generators was the development of fractures in the walls of "cold" headers collecting flows of heating medium from heat exchange tubes at the outlet of the equipment. When water levels in the secondary cooling circuit fluctuated in case of transients accompanied with variation of pressure and flow rates of the heat transferring medium, lowering of the level caused by faulty automation or human errors [8], situations developed when tubes in upper levels of the heating surface appeared to be above the level of water, heat transferring medium was not cooled in the tubes and "cold" header was becoming "hot" on certain parts of its surface area. This process was non-stationary because of instability both of the water level, and of the nature of boiling process [9-11] in the vicinity of outer wall of the "cold" header, in connection with which fluctuating 
thermal stresses developed in the parts of the wall in question.

Designers (OKB "Gidropress") and manufacturers (Machine-Building Plant of Podolsk) of horizontal steam generators undertook significant efforts for enhancing reliability of the equipment including the following:

- Replacement of header materials;

- Increased spacing of partitions between the holes for tubes in the headers within the critical area;

- Rejection of explosive tube expansion, which may cause additional stresses in the material.

Advancement of design of horizontal steam generators produced positive results. Currently, search for design solutions aimed at the enhancement of intensity of heat exchange processes both in the equipment of NPP as a whole and in NPP steam generators [12] is ongoing.

Nevertheless, principal shortcomings of the concept of steam generator of horizontal type and, first of all, impossibility of enhancement of per unit electric power of the equipment in excess of $50 \mathrm{MW}$, remain. This results in the situation when configurations of reactor facilities with horizontal steam generators requiring significant area under the containment shell of the primary cooling circuit are still used in the design of modern Russian VVER NPPs.

\subsection{Steam generators of vertical type}

The design concept of steam generators with vertical spatial orientation of vessel for NPP equipped with light water reactors (PWR) is well known. It was implemented on NPPs in different countries beginning from the middle of 1950s by Westinghouse, Combustion Engineering and other companies [13]. Working process in the vertical steam generator is achieved by repetitive natural circulation of steam-water mixture inside the vessel and in the annulus under significant dynamic pressure (due to the height of the equipment) [14-15]. This leads to high rate of circulation of water-steam mixture and to high steam quality in the mixture at the outlet from the bundle of tubes conducting heating medium, i.e. water of the NPP primary cooling circuit. Possibility emerges as the result to achieve in one reactor installation higher electric power equal to at least 500 MW.

Considerable experience of operation of vertical steam generators on foreign NPPs demonstrated both their advantages and shortcomings.

\subsubsection{Shortcomings of the design revealed in the process of operation on foreign NPPs}

The main disadvantages of design of steam generators of vertical type were manifested in the form of massive damages leading to the development of penetrating fractures in the tubes. The damages took place due to hideout corrosion in the region of flat bottom tube sheets, as well as due to deformation, corrosion and wear in the places where holdups of solid impurities were accumulated in the grids spacing tube bundles. This resulted in significant financial losses due to the replacement of about 300 items of equipment on the operated NPPs [16].

Steam generators of vertical type exist in Russia only as design documents [17]. This obstacle does not allow comprehensive enough and objective comparison of the horizontal and vertical types of the equipment because of the absence of first-hand experience of operation of vertical steam generators.

\subsubsection{Advantages of the design}

Vertical steam generators, which must be developed taking into consideration the experience of operation on foreign NPPs, including negative experience, possess the following advantages as compared to horizontal steam generators.

1. Improved arrangement of components under the containment shell, which results in the saving of materials and reduction of volumes of construction operations. Four horizontal steam generators installed under the containment shell in the modern VVER-1000 reactor installations occupy four times more area than four and, even more so, than two or three vertical steam generators with higher per unit capacity.

2. Absence of slurry holdups in stagnation zones along the secondary cooling circuit. There are no such zones in vertical steam generators, while they are present in horizontal steam generators in the region of lower tube rows.

3. Possibility to have tubes of the same length and uniformity of open area for penetration of steam-water mixture flow over the cross-section of the equipment due to the bend of platen of heat exchange surface along the involute curve result in the uniformity of heat absorption efficiency of the heating surface and improves operational conditions of the separator.

4. Application of two-stage (chevron and swirl-vane) system for separation of moisture with higher degree of steam drying (it is known that foreign separation devices are used in intermediate separators-superheaters of Russian nuclear power plants [18-19]).

5. "Hot" upper and "cold" lower parts of the vertical cylindrical header of the heating medium do not intersect the level of water in the secondary cooling loop.

6. Design of vertical single-phase pre-boiling steam generator allows organizing the so-called separate section, i.e. the heat exchanger for heating feed water to saturation temperature. This allows increasing average temperature difference in the equipment (Figure 2). Enhancement of parameters of the produced steam by $0.3-0.4 \mathrm{MPa}$ is achieved due to that. It is not possible to organize single-phase pre-boiling section in the horizontal steam generator because feed water is supplied to the upper part of the device and is mixed with boiler water generating steam-water mixture at saturation temperature. 


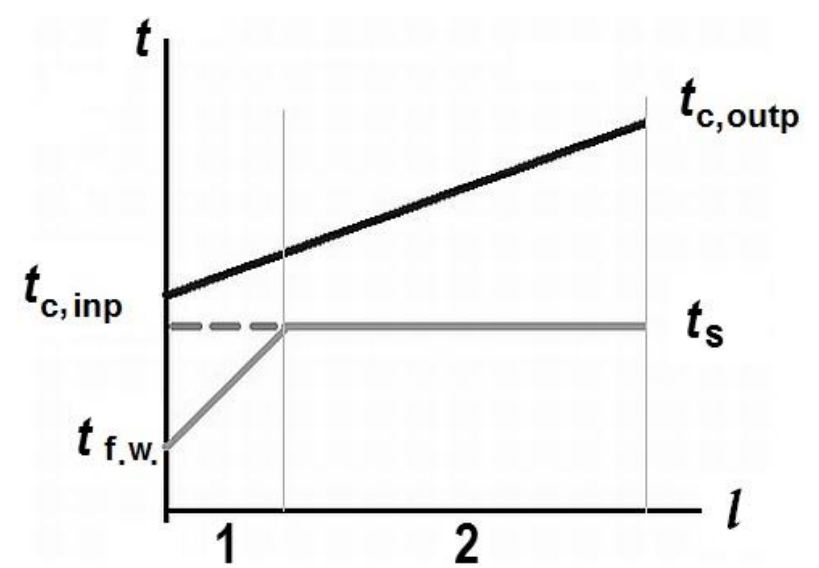

Fig. 2. Layout of distribution of temperatures of the heating medium (coolant) $(t \mathrm{c})$ and medium of the secondary loop (feed water) $\left(t_{\text {f.w. }}\right)$ in the steam generator: 1 - separate pre-boiling section; 2 - evaporation section; $\left(t_{\mathrm{S}}\right)$; - - - - steam generator without separate pre-boiling section.

Because of the thrust height of the circulation loop is much larger than in horizontal steam generators $(\sim 10 \mathrm{~m}$ versus $\sim 2.5 \mathrm{~m})$, the driving head of the natural circulation also becomes much greater. The velocity of the steam-water mixture and the intensity of its laving of the tube surfaces are also greater, which not only promotes intensification of heat-and-mass transfer in the inter-tubes space but also reduces the likelihood of steaming - stagnation of steam with degradation of heating emission, observed in tight tube bundles, as well as accumulation and settling of products of corrosion on the tubes.

In domestic designs, there is no thick flat, bottom tube board on which sludge can settle and whose materials undergo large temperature stresses because one part of the board is subjected to the hot heat-carrier flowing from the reactor and the other to cold heatcarrier. Since the collector walls are vertical, sludge is not retained on them and is washed off by the intensely circulating steam-water mixture.

The operating temperature conditions of the headers in dynamic regimes change: the evaporation time of the water from the steam generator after the feed water supply stops (both complete evaporation, i.e., emptying, as well as partial evaporation, i.e., to a definite level) is 1.5-1.6 times longer in a vertical steam generator then in a horizontal one. The design of a vertical steam generator is less sensitive to these irregularities, since the changes in the position of the level will be smaller.

\subsection{Analysis of operating experience of foreign steam generators}

Operational practice indicates that the pipe heating surface and the area of connection of the pipes with the pipe boards are crucial for the reliability of the steam generators [20].

The main events causing breakdowns in the elements of the heat exchange surface of steam generators are denting (due to clogging of the gaps between the tubes and holes in the spacer grids), tube wear, fatigue cracking, fretting (due to vibration), stress-corrosion (due to impurities of the secondary water), pitting, wastage. [21]

Long-term foreign experience in steam generators of nuclear power plants with PWR-type reactors operating has shown that at their design development, at determining the modes of their operation as part of the first and second circuits of nuclear power plants, the following conditions are important [22-24]:

- The material of the heat exchange tubes must be corrosion-resistant in the environment of both circuits;

- The design of the tube spacing devices (grids, strips) should exclude the possibility of accumulation of corrosion products in the secondary circuit and possible vibration wear of the tubes;

- In the second circuit, copper-containing alloys should be completely eliminated as structural materials of the equipment elements of this circuit;

- Since the formation of "sludge" in the second circuit is inevitable, means should be provided for purging volumes ("pockets", slots) where accumulation of "sludge" takes place, as well as the possibility of cleaning these volumes from "sludge" and washing the surfaces of the tube;

- The structural material of the heating coolant collectors should be not only high strength, but also sufficiently ductile (crack-resistant), since during operation of steam generators it is impossible to completely avoid the regime with time-varying loading of the collectors;

Careful observance of the given water-chemical regime of the second circuit must be ensured, and, if possible, in the second circuit should be excluded presence of chlorine ion (for example, together with feed water in case of leaks in the turbine condensers) and oxygen (in the presence of an air suction in these capacitors);

During operation of a nuclear power plant, it is necessary to exclude modes with "dips" in pressure in steam generators, as well as modes with "drops" of a level below the nominal;

During operation of a nuclear power plant, the possibility of water hammer in circuits must be excluded, especially condensation water hammer in the primary circuit, in which during normal operation there are no elastic volumes absorbing the energy of the shock in the reactor loops; the appearance of steam volumes with local boiling of water in the zone of low pressure creates the prerequisites for water hammer when the steam collapses in the zone of higher pressure.

\section{Conclusion}

The performed analysis of the development of concepts of horizontal and vertical steam generators for NPPs with Russian designed VVER pressurized light water reactors and with foreign PWR reactors allows formulating the following conclusions.

1. Fifty years of experience of operation of hundreds of horizontal and vertical steam generators revealed both positive and negative sides of both types of steam 
generator design. Both types of steam generators have deficiencies that are difficult to overcome.

2. A number of shortcomings of design, technological and operational mode nature were revealed in the process of operation of horizontal steam generators. Most part of the revealed drawbacks were removed during modernization of the equipment. Modern horizontal steam generators are characterized by the following non-removable drawbacks:

- Small height and volume of steam space above the evaporation mirror reducing efficiency of gravitational separation and prohibiting installation of swirl-vane separators between the perforated sheet and chevrontype separators thus reducing the capacity of the device [25];

- Complexity of organization in the tube bundle between two vertical headers of separate pre-boiling section cooled down with "cold" feed water;

- Equipment of reactor installation with horizontal steam generators is inferior in terms of compactness as compared with vertical steam generators and requires arrangement of bulky and cost intensive containment shell.

3. Since the design features of horizontal steam generators restrict the potential of enhancement of capacity of the power unit and parameters of generated steam, which negatively affects the financial performance of the reactor installation, development of reliable indigenous vertical steam generator in the nearest future may become one of the priority directions of further development of nuclear machine-building industry.

The following is suggested for the purpose of implementation of vertical steam generators in the Russian nuclear power generation industry based on high-power VVER reactors:

- Conducting testing of large-scale models of vertical steam generators;

- Development of design project and testing the pilot steam generator device in the composition of NPP with VVER-1200 reactors.

Coordination of the above tasks can be performed by the group of experts [26-30] representing design bureaus and research institutes and production facilities manufacturing heat exchange equipment for NPPs.

\section{References}

[1] N.G. Rassokhin, Steam generation equipment of nuclear power plants (Moscow, Energoatomizdat, 1987)

[2] L.F. Fedorov, V.F. Titov, N.G. Rassokhin, Steam generators of nuclear power plants (SaintPetersburg - Moscow, Energoatomizdat, 1992)

[3] N.B. Trunov, V.V. Denisov, S.A. Kharchenko, B.I. Lukasevich, Thermal Engineering 53, 1, (2006)

[4] N.B. Trunov, S.B. Ryzhov, S.E. Davidenko, Thermal Engineering 58, 3 (2011)
[5] B.I. Lukasevich, N.B. Trunov, Yu.G. Dragunov, S.E. Davidenko, Steam generators of VVER reactors for nuclear power plants (Moscow, Akademkniga, 2004)

[6] S.M. Dmitriev, D.L. Zverev, O.A. Bykh, Yu.K. Panov, N.M. Sorokin, V.A. Farafonov, Main equipment of NPP with freestanding thermal neutron reactors (Moscow, Mashinostroenie, 2013)

[7] N.A. Mahutov, K.V. Frolov, Yu.G. Dragunov, G.S. Vasilchenko, M.M. Gadenin, A.F. Getman, V.P. Gorbatykh, B.N. Dranchenko, V.V. Zatsarinny, G.P. Karzov, B.I. Lukasevich, I.V. Makarenko, L.V. Makarenko, Yu.K. Mikhalev, I.A. Razumovsky, A.N. Salin, A.V. Seleznev, A.V. Fomin, N.V. Shary, The bearing capacity of steam generators of pressurized water reactors (Moscow, Nauka, 2003)

[8] V.V. Bazhanov, A.A. Vavilov, S.S. Davydov, P.I. Zalevsky, V.A. Ivanov, Energomashinostroenie 4 (1988)

[9] A.A. Sinitsyn, D.F. Karpov, M.V. Pavlov, Theory and practice of heat transfer (Vologda: Vologda State Technical University, 2013)

[10] P.L. Kirillov, A.V. Zhukov, N.I. Loginov, Reference book on thermohydraulic calculations in nuclear power industry (Moscow, IzdAT, 2013)

[11] F.F. Tsvetkov, B.A. Grigoriev, Heat and mass transfer (Moscow, Moscow Energy Institute, 2011)

[12] Yu.F. Gortyshov, I.A. Popov, V.V. Olimpiev, A.V. Shchelchkov, S.I. Kaskov, Thermohydraulic efficiency of promising approaches to intensification of heat transfer in the channels of heat transfer equipment Intensification of heat transfer (Kazan, Center for Innovative Technologies, 2009)

[13] N.I. Kolev, Multiphase flow dynamics 5: nuclear thermal hydraulics (Switzerland, Springer International Publishing, 2015)

[14] V. Bezlepkin, I. Kukhtevich, S. Svetlov, S. Alekseev, A. Solodovnikov, A. Molchanov, Y. Krylov, A. Blagoveshchenskij, O. Krektunov, Tyazheloe Mashinostroenie 8 (2004)

[15] A. Blagoveshchenskii, S. Bor, M. Konovich, V. Mityukov, V. Sokolov, B. Shumskii, S. Vygovskii, A. Pinegin, L. Bogachek, V. Bai, N. Ignat'ev, Thermal Engineering 51, 2 (2004)

[16] N.B. Trunov, S.E. Davidenko, V.V. Denisov, VANT: Obespechenie bezopasnosti AES,Reaktornye ustanovki s VVER 9 (2005)

[17] A.V. Sudakov, V.V. Silin, M.E. Lebedev, B.S. Fokin, B.K. Danilin, M. Ya., Proc. of the 6th Int. scientific-practical Conf. (Moscow, Spetskniga Publ., 2012) 
[18] V.V. Legkostupova, A.V. Sudakov, St. Petersburg Polytechnic University Journal of Engineering Science and Technology 23, 3 (2017)

[19] V.V. Legkostupova, A.V. Sudakov, St. Petersburg Polytechnic University Journal of Engineering Science and Technology 4, 254, (2016)

[20] R. Fournier, M. Thibodeau, C. T. French, Measurement of steam generator or reactor vessel moisture carryover using a non-radioactive chemical tracer, International Conference on Nuclear Engineering 43536 (2009)

[21] B. John, S.P. Dharne, S.G. Ghadge, S.A. Bhardwaj, Evolution of 540 MWth steam generator from 434 MWth (2005)

[22] X. Kong, J. Zhang, Y. Xiao, L. Qian, L. Su, B. Chen, M. Xu, Performance optimization for steam generator level control based on a revised simultaneous perturbation stochastic approximation algorithm, 3rd International Conference on Intelligent Green Building and Smart Grid (IGBSG) IEEE (2018)

[23] S.M. Hoseyni, F. Di Maio, E. Zio, Conditionbased probabilistic safety assessment for maintenance decision making regarding a nuclear power plant steam generator undergoing multiple degradation mechanisms, Reliability Engineering \& System Safety 191, 106583 (2019)

[24] G. Yang, V. Pointeau, E. Tevissen, A. Chagnes, A review on clogging of recirculating steam generators in Pressurized-Water Reactors. Progress in Nuclear Energy 97 (2017)

[25] N.B. Trunov, B.I. Lukasevich, D.O. Veselov, Yu.G. Dragunov, Atomic Energy 105, 3 (2008)

[26] N.D. Agafonova, I.L. Paramonova, Thermal Engineering 60, 3 (2013)

[27] S. Alekseev, Y. Ilyukhin, V. Kukhtevich, I. Paramonova, S. Svetlov, V. Sidorov, High Temperature 37, 4 (1999)

[28] N.D. Agafonova, I.L. Paramonova, Thermal Engineering 61, 8 (2014)

[29] N.D. Agafonova, I.L. Paramonova, Journal of Engineering Physics and Thermophysics 89, 4 (2016)

[30] M. Gorpinyak, A. Solodov, Thermal Engineering 66, 6 (2019) 